\title{
Experimental and Numerical Study on the Flow Ripple of Circular-arc Gear Pumps Considering the Center Distance Deviation
}

Xiaoling Wei ( $\square$ weixiaolng800@163.com )

PLA Rocket Force University of Engineering Department of Missile Engineering https://orcid.org/00000003-1729-4300

\section{Yongbao Feng}

PLA Rocket Force University of Engineering Department of Missile Engineering

\section{Zhenxin He}

PLA Rocket Force University of Engineering Department of Missile Engineering

Ke Liu

PLA Rocket Force University of Engineering Department of Missile Engineering

\section{Original Article}

Keywords: Circular-arc Gear Pump, Center Distance, Flow Ripple, Pressure Ripple

Posted Date: August 31st, 2021

DOI: https://doi.org/10.21203/rs.3.rs-841282/v1

License: (9) This work is licensed under a Creative Commons Attribution 4.0 International License. Read Full License 


\title{
Experimental and Numerical Study on the Flow Ripple of Cir- cular-arc Gear Pumps Considering the Center Distance Devia- tion
}

\author{
Xiaoliing Wei ${ }^{1, *}$, Yongbao Feng ${ }^{1}$, Zhenxin $\mathrm{He}^{1}$ and Ke Liu ${ }^{1}$ \\ 1. PLA Rocket Force University of Engineering, 710025 X'an, China; \\ *Correspondence: weixiaoling800@163.com
}

Abstract: Novel circular-arc gear pumps effectively solve the problems of oil trapping and flow pulsation experienced with traditional gear pumps. However, the center distance deviation associated with assembly and installation during gear pump processing has an important influence on the outlet pressure pulsation characteristics of circular-arc gear pumps. First, the circular-arc tooth profile equation, conjugate curve equation and meshing line equation were derived to design the circular-arc gear meshing and center distance deviation functions. Second, the circular-arc gear tooth profile was accurately obtained. Then, a pressure pulsation characteristic simulation model for the novel circulararc gear pumps considering the center distance deviation was established. The results show that with the increase of center distance deviation, the outlet flow rate of the arc gear pump increases first and then decreases greatly. Moreover, the center distance deviation has little effect on the independent tooth cavity pressure. Finally, the proposed fluid dynamic model is used to simulate a commercial circular-arc gear pump, which was tested within this research for modeling validation purposes. The comparisons highlight the validity of the proposed simulation approach.

Keywords: Circular-arc Gear Pump, Center Distance, Flow Ripple, Pressure Ripple

\section{Introduction}

Among the existing positive displacement pumps, external gear pumps are mainly used in systems such as fuel injection systems, automotive lubrication and transmission systems, and high-pressure cleaning and fluid delivery systems [1]. The main advantages of this type of pump are that the manufacturing cost is low, the packaging is compact, it can operate at high pressures, it is suitable for fluids in the high-viscosity range, and it has high resistance to fluid variations and cavitation. However, the traditional involute external gear pump is limited by uneven outlet flows due to an oil trapping phenomenon, which causes the pump to produce noise and vibrations [2].

Researchers have begun to study unconventional tooth profiles, including arc gears, to further reduce the pulsation of the outlet flow. Morselli [3] first described an arc gear pump in a patent, and Chen and Yang [4] published the first research results obtained with an arc tooth profile in an external gear pump. Zhou Yang et al. [5] discussed the tooth profile design in detail and combined involute and arc tooth profiles. Manring, Kasaragadda [6], Huang, Lian [7], and others proposed a basic method to link spur gear tooth profile parameters with motion flow pulsation. Vacca et al. [8] applied this method to circular arc gear pumps and theoretically analyzed determined that the outlet flow pulsation for circular arc gear pumps was zero; however, experimental research results indicated that circular arc gear pumps yielded very small pressure and flow pulsations. R. Massimo [9] reviewed different flow simulation methods to simulate the flow of gear drives and external gear pumps before 2017. For the lumped parameter model, the flow simulation of different pumps based on the control volume was analyzed, the control equation was given, and the latest research results considering the effect of the interaction of fluid and mechanical components on leakage were introduced. Dipen $\mathrm{R}$ et al. [10] simulated the internal fluid motion state of an involute external gear pump through FLUENT software, and compared them through experiments, and obtained the good results.

The center distance deviation in the assembly of the circular-arc gear pump changes the contact position and contact area of the gear tooth surface, thus affecting outlet pressure pulsation and resulting in vibration and noise. Therefore, it is necessary to study how the center distance deviation affects the dynamic characteristics of the circular-arc gear pump, which will help to guide the gear design and machining of the circular-arc gear pump, so as to lay a foundation for giving full play to its performance advantages. In this paper, according to the principle of spatial meshing, we derived the end face tooth profile equation, conjugate tooth profile equation and meshing line equation for circular-arc gears. On this basis, the effects of the tooth profile and center distance deviation on flow pulsation and pressure pulsation are studied for a circular-arc gear pump, which provided the theoretical guidance for the circular-arc gear design. 


\section{The Center distance deviation and the Meshing Position}

Figure 1 shows the change in the meshing position with and without center distance deviation when the arc gears are meshed. The driving gear produces an offset position $\Delta L$, and the offset position of the driven gear is zero. Figure 1(a) shows that the theoretical center distance is $L$, and the driving gear and the driven gear mesh at point Mo when there is no center distance deviation. The driving gear and the driven gear mesh at point $\mathrm{M}_{1}$ when there is a center distance deviation $\Delta L$ (which is positive here). Figure $\mathbf{1}(\mathbf{b})$ is an enlarged view of the meshing position.

Because the driving and driven gears may have offset positions in reality and the operation process, CNC machining technology and installation process are characterized by inherent errors, the center distance deviations in this article are $0,0.01 \mathrm{~mm}$, and $0.02 \mathrm{~mm}$.

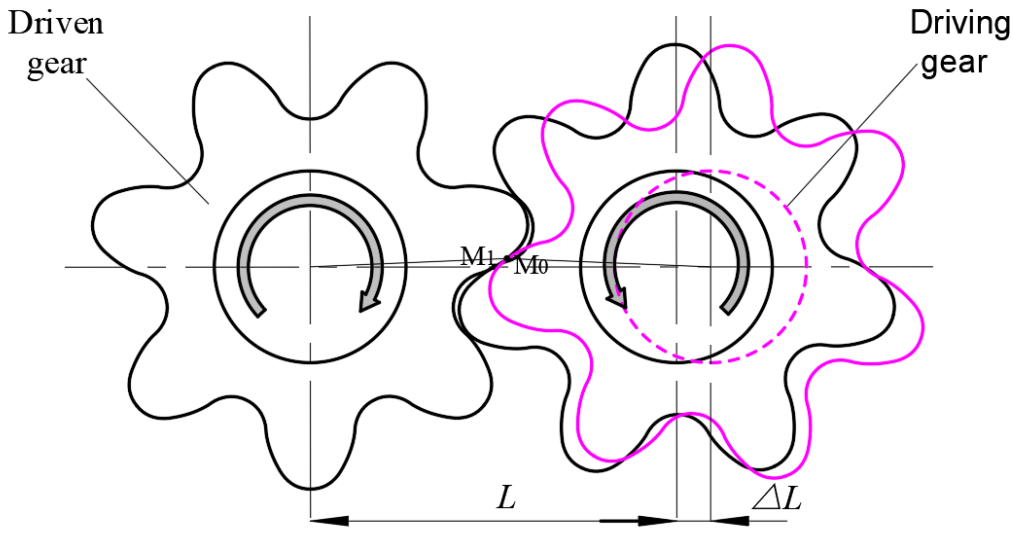

(a)

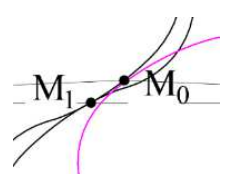

(b)

Figure 1. Schematic diagram of basic tooth profile for the meshing of arc gears with and without center distance deviation: (a) the driving gear and the driven gear mesh at point $\mathrm{M}_{0}$ when there is no center distance deviation. The driving gear and the driven gear mesh at point $\mathrm{M}_{1}$ when there is a center distance deviation; $(\mathbf{b})$ is an enlarged view of the meshing position.

\section{Geometric Modeling}




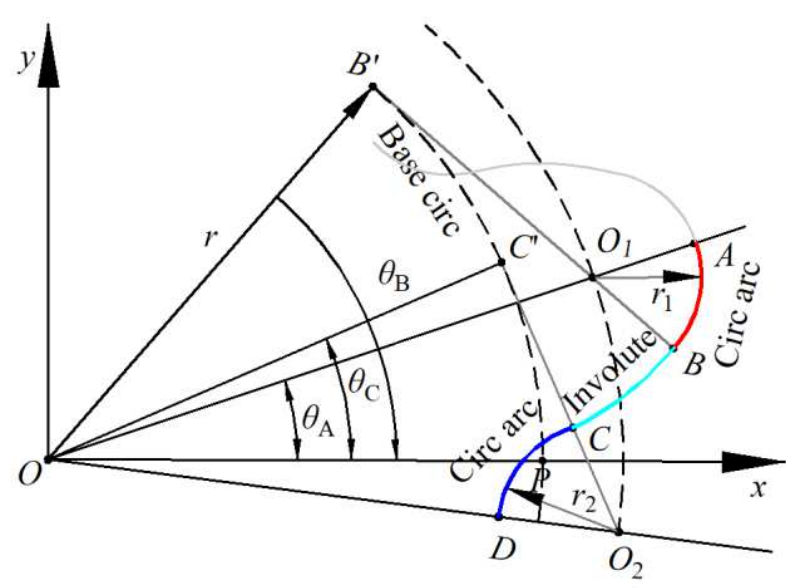

(a)

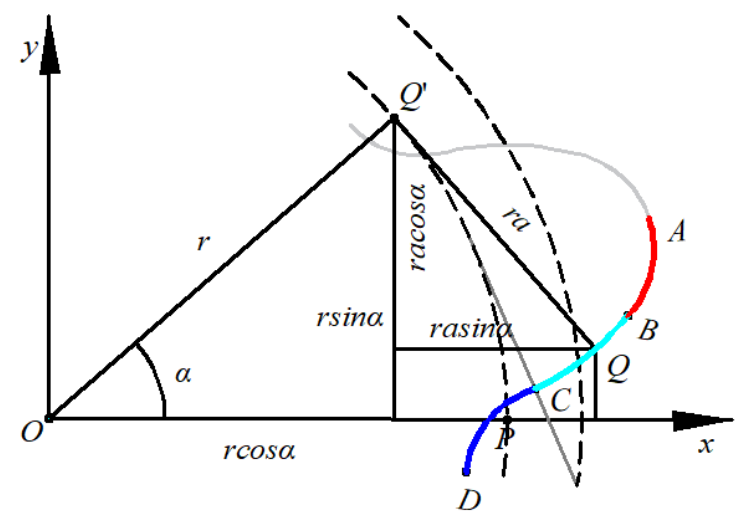

(b)

Figure 2. Gear tooth profile: (a) the curve is composed of the involute curve $B C$ and two arc curves $A B$ and $C D$, where the two arc curves are tangential to the involute curve at points $B$ and $C ;(b)$ Description the relationship of the AB section of the arc curve, the involute $\mathrm{BC}$ section, and the $\mathrm{CD}$ section of the arc curve.

From Figure 2(b), the involute BC section equation is obtained:

$$
\left.\begin{array}{l}
x_{12}=r \cos \alpha+r \alpha \sin \alpha \\
y_{12}=r \sin \alpha-r \alpha \cos \alpha
\end{array}\right\}
$$

The equation of the $\mathrm{AB}$ section of the arc curve is:

$$
\left.\begin{array}{l}
x_{11}=\frac{r \cdot \cos \theta_{A}}{\cos \left(\theta_{A}-\theta_{C}\right)}+r_{1} \sin \varphi_{1} \\
y_{11}=\frac{r \cdot \sin \theta_{A}}{\cos \left(\theta_{A}-\theta_{C}\right)}+r_{1} \cos \varphi_{1}
\end{array}\right\},
$$

where $\varphi_{1}$ is a parameter related to the arc angle of the $\mathrm{AB}$ segment. The $\mathrm{CD}$ segment equation of the arc curve is:

$$
\left.\begin{array}{r}
x_{13}=\frac{r \cdot \cos \left(\theta_{A}-\frac{\pi}{N}\right)}{\cos \left(\theta_{B}-\left(\theta_{A}-\frac{\pi}{N}\right)\right)}+r_{2} \sin \varphi_{2} \\
y_{13}=\frac{r \cdot \sin \left(\theta_{A}-\frac{\pi}{N}\right)}{\cos \left(\theta_{B}-\left(\theta_{A}-\frac{\pi}{N}\right)\right)}+r_{2} \cos \varphi_{2}
\end{array}\right\},
$$

where $\varphi_{2}$ is a parameter of the arc angle of the CD segment. Then, the addendum radius $r_{a}$ is:

$$
r_{a}=r \cdot \sec \left(\theta_{B}-\left(\theta_{A}-\frac{\pi}{N}\right)\right)-r \cdot \theta_{B}
$$

The root radius $r_{f}$ is

$$
r_{f}=r \cdot \sec \left(\theta_{c}-\theta_{A}\right)-r \cdot \tan \left(\theta_{c}-\theta_{A}\right)+r \cdot \theta_{c}
$$

Since the tooth profile is formed by the smooth connection between the arcs $A_{1} B_{1}$ and $C_{1} D_{1}$ and the involute curve $B_{1} C_{1}$ and the connecting points of the arc and the involute are $B_{1}$ and $C_{1}$, the points $B_{1}$ and $C_{1}$ are both on the arc and the involute curve; thus, the three curves are connected. Therefore,

$$
\left.\begin{array}{l}
\varphi_{1 B}=-\arctan \theta_{B} \\
\varphi_{2 C}=-\arctan \theta_{C}
\end{array}\right\},
$$

where 


$$
\left.\begin{array}{l}
\theta_{B}=\tan \alpha+\frac{\pi}{2 N} \\
\theta_{C}=\tan \alpha-\frac{\pi}{2 N}
\end{array}\right\}
$$

The above formula sets indicate that the tooth profile of the end face of the arc gear pump is influenced by the base radius $r$; the opening angles $\theta_{\mathrm{A}}, \theta_{\mathrm{c}}$ and $\theta_{\mathrm{B}}$; and the number of teeth.

\section{2. Conjugate Arc Tooth Profile Equation}

After determining the curve equation for a section of the driving gear, the conjugate curve equation of the driven gear can be obtained by the principle of conjugate gear meshing [9]. The specific solution process is as follows.

As shown in Figure 2(a), points $\mathrm{O}_{1}$ and $\mathrm{O}_{2}$ are the centers of the gears, and point $\mathrm{P}$ is the pitch point of the gear pair. The pitch circle radius is $r_{1}$, and the center distance is $a\left(\mathrm{O}_{1} \mathrm{O}_{2}=2 r_{1}\right)$. We take $\mathrm{O}_{1}$ as the origin of the coordinate system $\mathrm{S}_{1}\left(\mathrm{O}_{1}-x_{1}, y_{1}\right)$, which is fixed, connected to gear 1 and rotates with gear $1 . \mathrm{O}_{2}$ is the origin of the coordinate system $\mathrm{S}_{2}\left(\mathrm{O}_{2}-\right.$ $\left.x_{2}, y_{2}\right)$, which is fixed, connected to gear 2 and spins with gear 2 . We use point $P$ as the origin to fix the coordinate system $\mathrm{S}_{\mathrm{P}}(\mathrm{P}-x, y)$ on the meshed two-gear transmission plane. At the starting position, the coordinate axes $y_{1}$ and $y_{2}$ coincide with $y$, and the coordinate axes $x_{1}$ and $x_{2}$ are parallel to $x$.

The known tooth profile $A B C D$ is fixed and connected with the coordinate system $S_{1}\left(\mathrm{O}_{1}-x_{1}, y_{1}\right)$. Gear 1 and the tooth profile $A B C D$ rotate counterclockwise together. The rotation angle of gear 1 is positive in the counterclockwise direction. We can assume that the angle between the tangent at a point $N\left(x_{1}, y_{1}\right)$ on the tooth profile ABCD and the axis $x_{1}$ is $\gamma$. The normal line intersects the pitch circle of gear 1 at point $\mathrm{N}^{\prime}$, and the angle between the straight line $\mathrm{O}_{1} \mathrm{~N}^{\prime}$ and the tangent at point $\mathrm{N}$ is $\theta$. Each point on the tooth profile $\mathrm{ABCD}$ is a contact point. By transforming coordinates of arc $\mathrm{AB}$, the involute curve $B C$, and the arc $C D$ into coordinate system $S_{2}\left(\mathrm{O}_{2}-x_{2}, y_{2}\right)$, which is fixed and connected to gear 2 , we can obtain the conjugate gear tooth profile equation:

$$
\left[\begin{array}{l}
x_{2} \\
y_{2} \\
t_{2}
\end{array}\right]=\left[\begin{array}{ccc}
\cos 2 \varphi & -\sin 2 \varphi & 2 r_{1} \sin \varphi \\
\sin 2 \varphi & \cos 2 \varphi & -2 r_{1} \cos \varphi \\
0 & 0 & 1
\end{array}\right]\left[\begin{array}{l}
x_{1} \\
y_{1} \\
t_{1}
\end{array}\right]
$$

where $t$ is equal to 1 .

\section{3. Meshing Line Equation}

The trajectory of the contact point in the fixed coordinate system $\mathrm{SP}_{\mathrm{P}}(\mathrm{P}-x, y)$ is the meshing line. Based on coordinate transformation, the meshing line equation can be obtained:

$$
\left[\begin{array}{l}
x \\
y \\
t
\end{array}\right]=\left[\begin{array}{ccc}
\cos \varphi & -\sin \varphi & 0 \\
\sin \varphi & \cos \varphi & -r_{1} \\
0 & 0 & 1
\end{array}\right]\left[\begin{array}{l}
x_{1} \\
y_{1} \\
t_{1}
\end{array}\right]
$$

where

$$
\left.\begin{array}{l}
\cos \theta=\frac{x_{1} \cos \gamma+y_{1} \sin \gamma}{r_{1}} \\
\varphi=\frac{\pi}{2}-(\gamma+\theta) \\
\tan \gamma=\frac{d y_{1}}{d x_{1}} \\
r_{1}=\frac{r_{a}+r_{f}}{2}
\end{array}\right\}
$$

By determining the coordinates of a point on the tooth profile ABCD and calculating the angle $\gamma$ between the tangent of this point and axis $x_{1}$ based on (10), the angle of rotation when the point becomes the contact point can be calculated. To ensure continuous transmission for the gear pump, this paper focuses on half of the pitch angle $2 \pi / \mathrm{N}$ :

$$
\beta \geq \frac{\pi}{N}
$$




\subsection{Governing Equation}

Within each tooth space, the following pressure build-up equation is solved for the pressure dynamics [11]:

$$
\frac{d p}{d t}=\frac{K}{V}[Q-\dot{V}]
$$

where $K$ is the bulk modulus, $V$ is the instantaneous tooth space volume, $\dot{V}$ is the change rate of tooth space volume, while $Q$ is the flow in the tooth space. Each tooth space solves its own pressure build-up equation, i.e. Eq. (12).

The turbulent orifice connections of each tooth space are considered in this paper, similarly to the approach of [12]. For this turbulent orifice connection, the flowrate is given by:

$$
Q=C_{q} \cdot A \cdot \sqrt{\frac{2|\Delta p|}{\rho}}
$$

Where the $C_{q}$ is the discharge coefficient, $A$ is the orifice opening area, $\Delta p$ is the pressure difference between displacement chambers at both ends, and $\rho$ is the density taken at the average pressure between displacement chambers at both ends. To take the influence of the Reynolds number on the discharge into account, the discharge coefficient is modeled as [13].

$$
C_{q}=C_{\text {qmax }} \cdot \tanh \left(\frac{2 \lambda}{\lambda_{\text {crit }}}\right)
$$

where the $C_{q \max }$ is the user defined empirical maximum flow coefficient, and the typical value used is 0.7 . The hyperbolic tangent function is generally used to fit the case of low Reynolds number. The $k$ is the predictive quantity of Reynolds number, which is estimated as:

$$
\lambda=\frac{D_{h} \cdot u}{v}=\frac{D_{h}}{v} \sqrt{\frac{2 \Delta p}{\rho}}
$$

The typical value of the critical Reynolds number $\lambda_{\text {crit }}$ for orifice plate is 1000 [13]. When the Reynolds number is low, the hyperbolic tangent function makes the flow rate change linearly with the pressure difference and returns to the state of flow field. The $D_{h}$ is the hydraulic diameter of orifice opening, and the velocity at orifice is estimated as

$$
u=\sqrt{\frac{2 \Delta p}{\rho}}
$$

\subsection{Implementation}

The overall numerical model of an arc gear pump is established, as shown in Figure 3. The 1D model of the arc gear pump is automatically generated so that the arc tooth profile can be accurately obtained. The center distance deviation was considered in advance. 


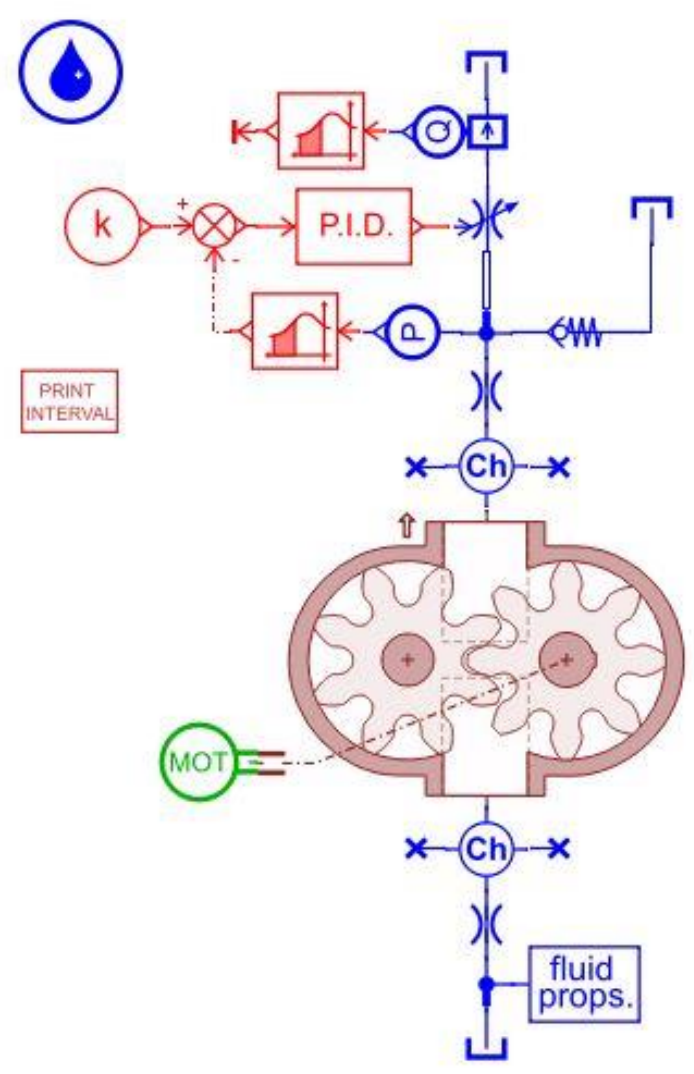

Figure 3. The overall numerical model of an arc gear pump.

We established a three-dimensional model of the arc gear pump and then created a 1D model of the arc gear pump according to the CAD import function. It should be noted that the center of the coordinate system of the arc gear pump must be located at the 1D center of the driving gear, and the arc gear rotates counterclockwise. According to the 1D model of the arc gear pump, the initial associated parameters can be obtained, as shown in Table 1. The initial parameters of the overall simulation model were set as shown in Table 2.

Table 1. 1D model initial correlation parameters of the arc gear pump.

\begin{tabular}{cc}
\hline Parameters & Values \\
\hline Center distance & $39.17 \mathrm{~mm}, 39.18 \mathrm{~mm}$, and $39.19 \mathrm{~mm}$ \\
Initial pressure & $0 \mathrm{bars}$ \\
Number of teeth of gear & 7 \\
Gear thickness & $31 \mathrm{~mm}$ \\
Teeth clearance & $0.1 \mathrm{~mm}$ \\
Radial clearance & $0.001 \mathrm{~mm}$ \\
Length gap tooth & $0.3 \mathrm{~mm}$ \\
Width gap tooth & $0.4 \mathrm{~mm}$ \\
Height left gap tooth & $0.001 \mathrm{~mm}$ \\
Height right gap tooth & $0.001 \mathrm{~mm}^{1}$ \\
\hline
\end{tabular}

${ }^{1}$ Data are from the 1D model of the arc gear pump.

Table 2. Initial parameter values for the arc gear pump simulation.
144 145 146

\section{Values}

ISO VG 46 oil - Mobil DTE 25

$30^{\circ} \mathrm{C}$
Fluid property file

Temperature 


\section{Shaft speed}

$1480 \mathrm{rev} / \mathrm{min}^{2}$

${ }^{2}$ Data are from the initial parameters of the overall simulation model in AMESim.

When the simulation model of the arc gear pump was established, each tooth volume during the meshing of the driving gear and the driven gear was determined, as shown in Figure 4. The driving gear (right) drives the driven gear (left) to rotate counterclockwise and perform oil suction and discharge functions for the arc gear pump. The volumes enclosed by the dotted lines are the volumes of the fourth tooth of the driving gear and the driven gear, denoted as Dr\#4 and Dn\#4. Based on counterclockwise rotation, all the intertooth volumes of the pump are marked. Notably, Dr represents the driving gear, Dn represents the driven gear, and $i(i=1,2 \ldots 7)$ represents the $i$-th intertooth volume.

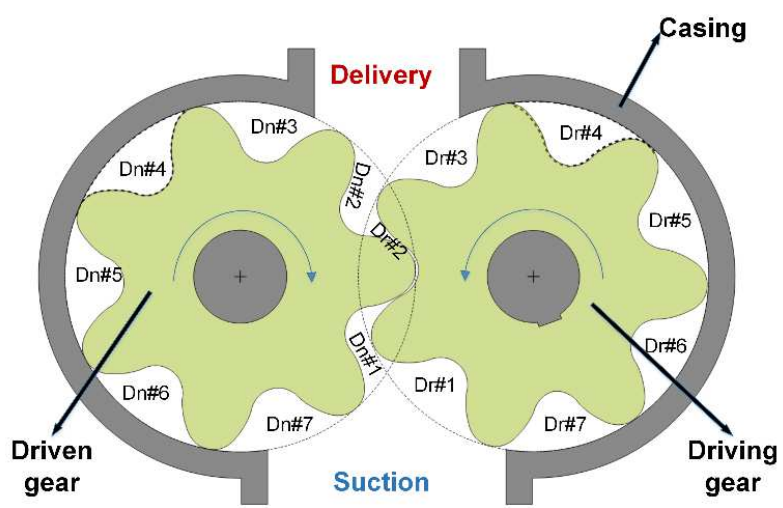

Figure 4. Working principle diagram of the arc gear pump. The driving gear is on the right, and the driven gear is on the left. The driving gear (right) drives the driven gear (left) to rotate counterclockwise.

\section{Model Results and Validations}

Pressure ripple and flow ripple have been carried out in full flow condition and in zero flow condition with outlet pressures of 0,20 , and 80 bar and constant rotational speed of $600 \mathrm{rpm}$ and $1480 \mathrm{rpm}$ in different Center Distances.

\subsection{Simulation results on the reference pump and discussion}

\subsubsection{Effect of Different Center Distances on Flow Rates}

Figure 5 shows the influence of the center distance deviation on the pulsation of the pump outlet flow. Under the light load condition (600rpm, 20bar), with the increase of center distance deviation, the outlet flow rate of the arc gear pump increases first and then decreases greatly. When the center distance deviation is within $0.01 \mathrm{~mm}$, the outlet flow rate of the arc gear pump increases gradually and has good dynamic characteristics. As the center distance deviation increases to $0.02 \mathrm{~mm}$, the outlet flow rate of the arc gear pump decreases greatly, and the dynamic characteristics of this pump become worse. Under the medium load condition (1480rpm, 80bar), with the increase of center distance deviation, the outlet flow rate of arc gear pump shows the same characteristics as the light load condition. In conclusion, the arc gear pump is more sensitive to the center distance deviation. When the center distance deviation is controlled within a certain range, the arc gear pump has better dynamic characteristics. Therefore, in order to give full play to the good transmission performance of the arc gear pump and prevent excessive dynamic impact due to the center distance deviation, the dynamic response caused by the center distance deviation can be adjusted by optimizing the machining accuracy and assembly accuracy of the arc gear. 


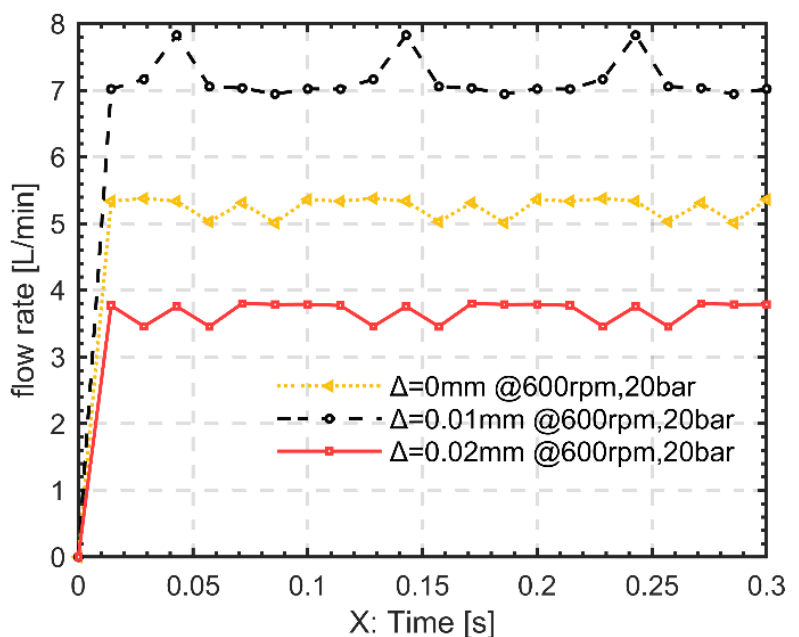

(a)

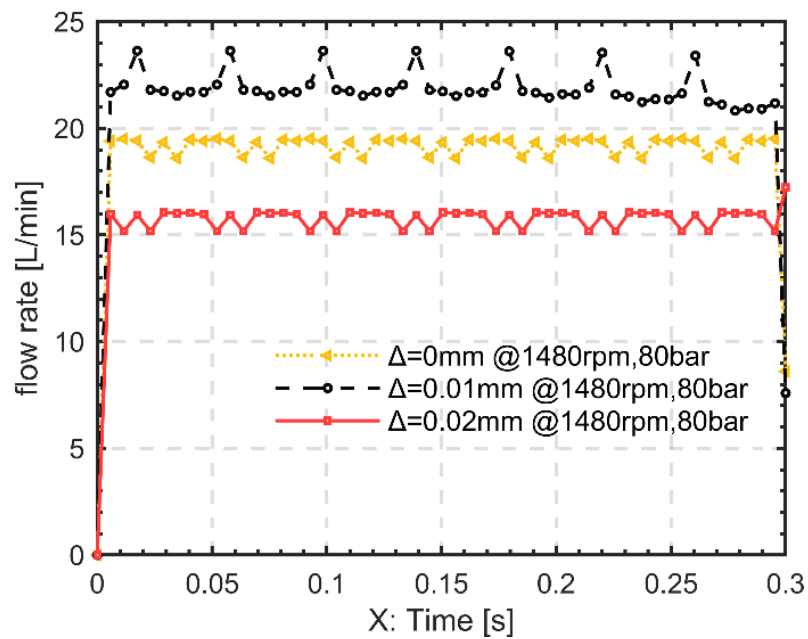

(b)

Figure 5. The influence of the center distance deviation on the pulsation of the pump outlet flow: (a) the light load condition is $600 \mathrm{rpm} \& 20 \mathrm{bar}$; (b) the medium load condition is $1480 \mathrm{rpm} \& 80 \mathrm{bar}$.

\subsubsection{Effect of Different Center Distances on Pressure}

The pump speed was set to $1480 \mathrm{r} / \mathrm{min}$, and the pressure changes in each tooth volume for the driving and driven gears were observed with center distance deviation, shown in Figure 6. When the arc gear pump starts to run, the first tooth volume of the driving gear is completely connected to the pump inlet, and the pressure associated with the tooth volume is the same as the inlet pressure. Approximately $90 \%$ of the first tooth volume of the driven gear is connected to the pump outlet. Thus, at initial moment, pressure in the volume is lower than the outlet pressure. The pressure in the tooth volume then gradually decreases with the operation of the pump. As the center distance deviation gradually increases, the pressure in the first volume of the driving gear does not change, and the pressure in the first volume of the driven gear has micro oscillations. When the arc gear pump continue to run, $95 \%$ of the second tooth cavity of the driving gear and driven gear are connected to the pump outlet. At this time, the pressure in the tooth cavity is equal to the pump outlet pressure. As the center distance deviation gradually increases, the pressure in the second cavity of the driving and driven gears has no change. The third tooth cavity and of the driving gear is completely connected to the pump outlet. At this time, the pressure in the tooth cavity is the same as the pump outlet pressure. The third tooth cavity of the driven gear is an independent tooth cavity that is not connected to any port of the pump. The pressure in the tooth cavity gradually reaches the outlet pressure. As the center distance deviation gradually increases, the pressure in the third cavity of the driving gear has no change. The 4th tooth cavity and of the driving gear and driven gear are the independent tooth cavities that are not connected to any port of the pump. As the center distance deviation gradually increases, the pressure in the third cavity of the driving gear has no change. The 7th tooth cavity of the driving and driven gears are connected to the pump inlet. The pressure on the driving gear smoothly decreases.

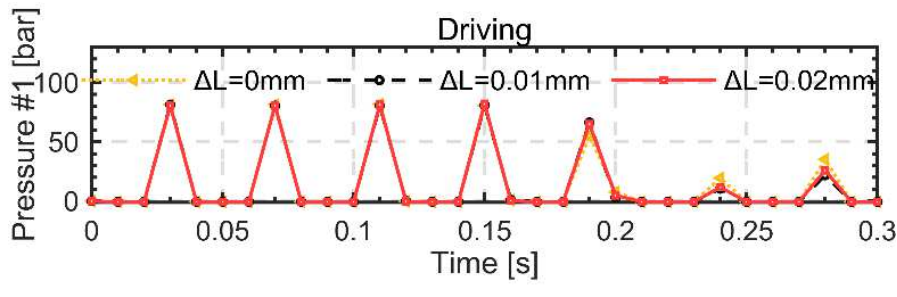

(a)

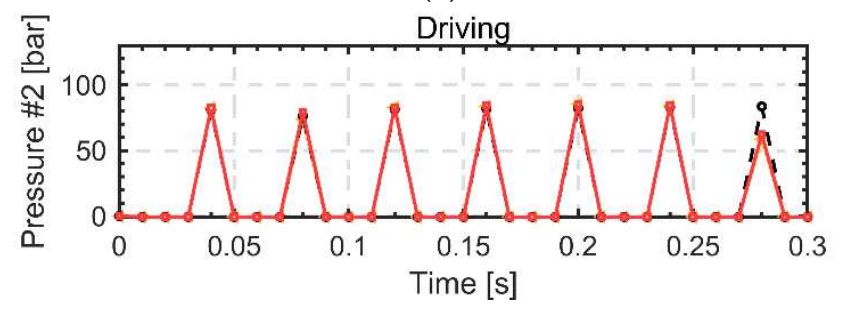

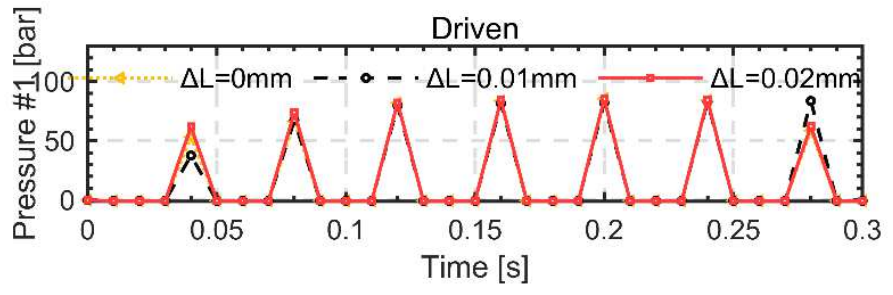

(b)

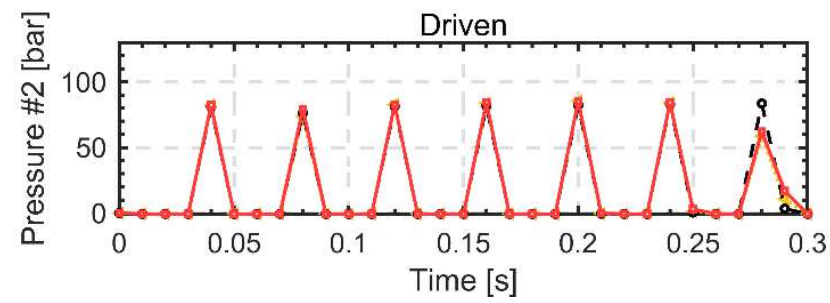


(c)

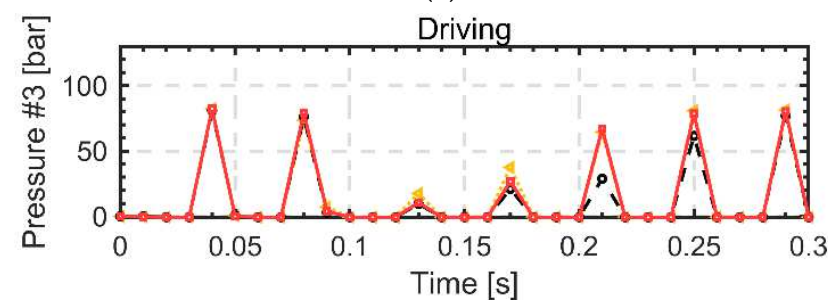

(e)

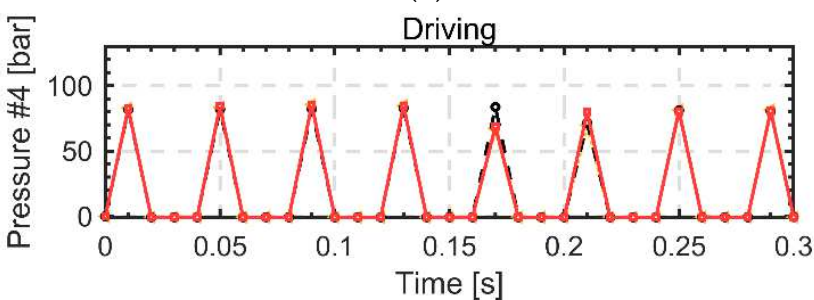

(g)

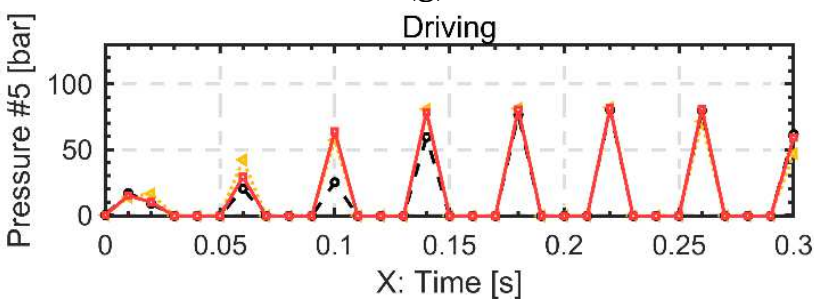

(m)

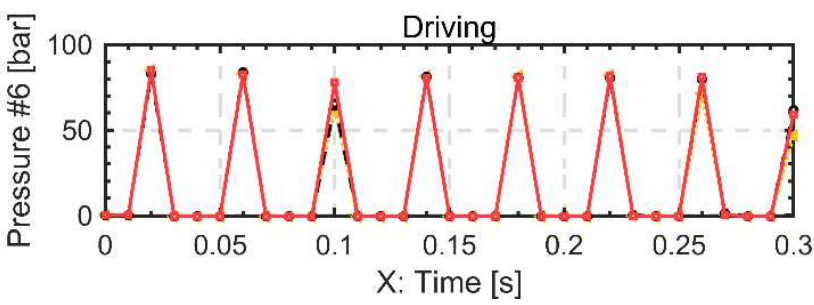

(p)

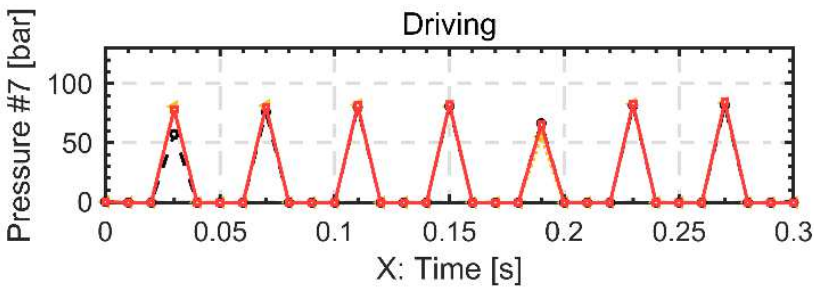

$(\mathrm{r})$ (d)

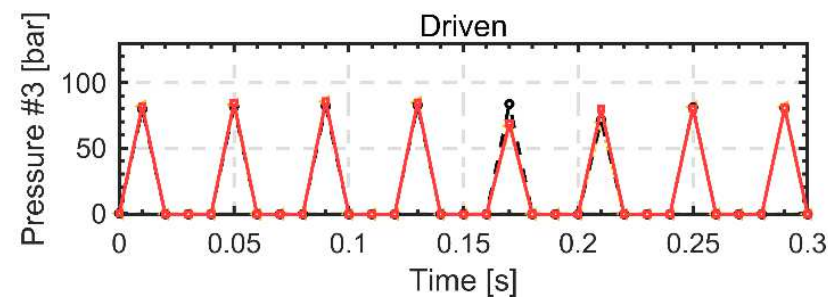

(f)

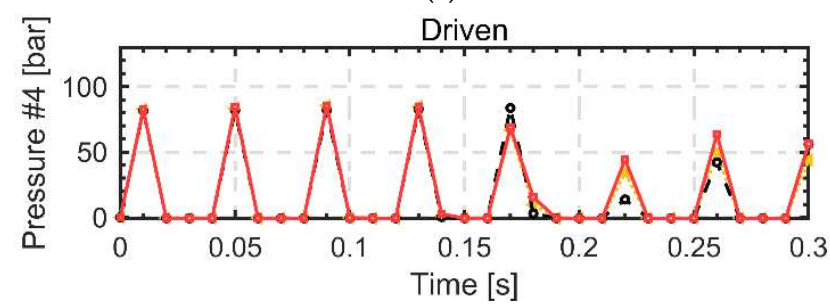

(h)

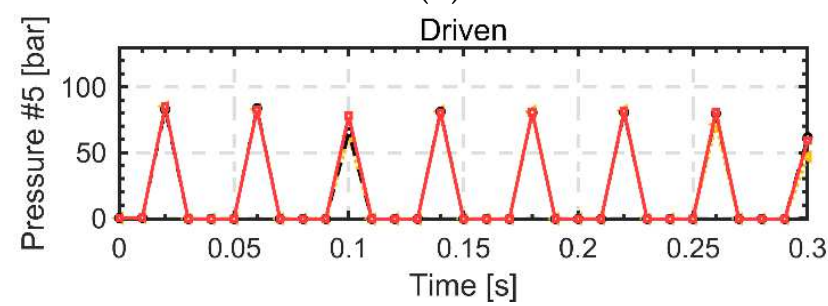

(n)

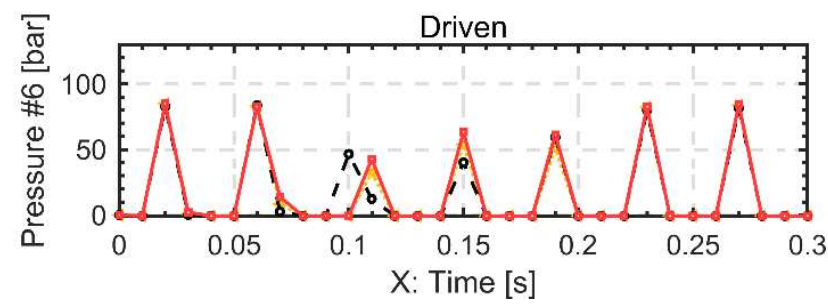

(q)

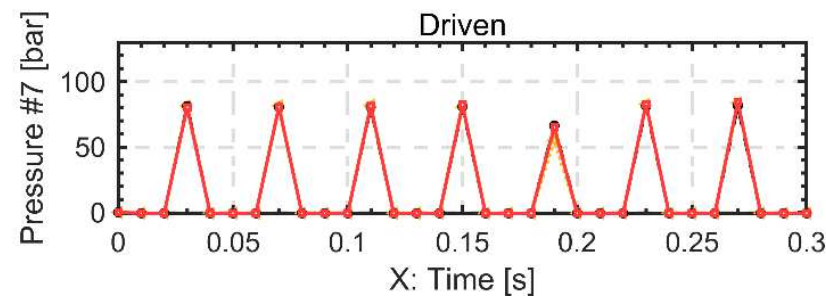

(s)

Figure 6. The effect of center distance deviations on pressure for each tooth cavity at 1480rpm and 80bar.

\subsection{Experimental measurement and validation}

Experiments were conducted on a commercial circular-arc gear pump produced by Settima. The ISO schematic of the experimental setup is shown in Figure 7. The model under test was a 7-tooth gear pump of $32 \mathrm{~cm}^{3} / \mathrm{rev}$ displacement. The tests were performed at the Shandong Shijing Machinery Co.Ltd, shown in Figure 8. The information about the sensors used in the setup is presented in the Table 3. The fluid used during the test is the ISO VG 46 hydraulic oil. 


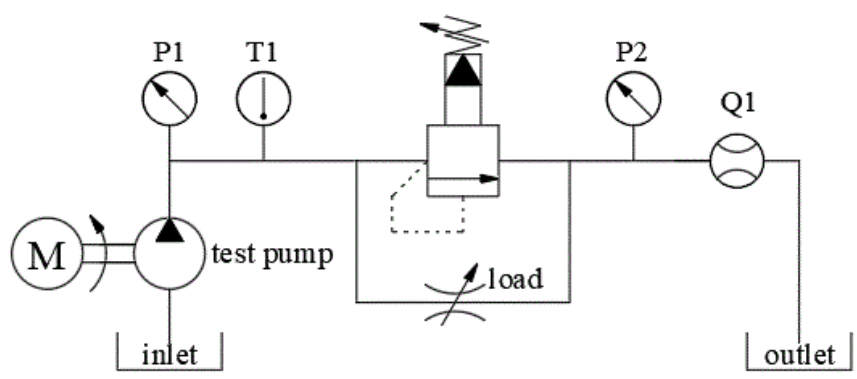

Figure 7. ISO schematic of the experimental setup.

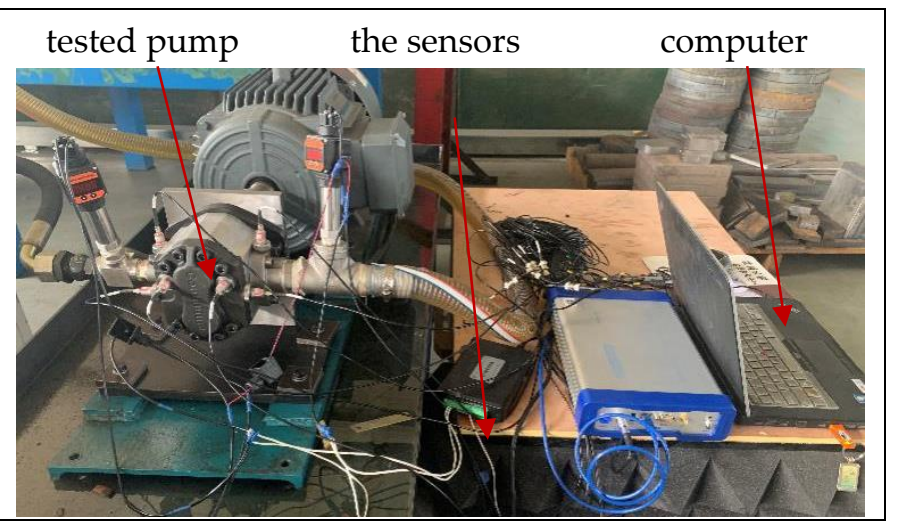

Figure 8. The experiment setup.

Table 3. Senor data of the experimental setup.

\begin{tabular}{cclc}
\hline Name & Senor type & Range & Precision \\
\hline P1 & MIK-P300-30MPa-V1-B1-C1-J1P1 & $0 \sim 300 \mathrm{bar}$ & $0.5 \%$ \\
P2 & MIK-P300-30MPa-V1-B1-C1-J1P1 & $0 \sim 300 \mathrm{bar}$ & $0.5 \%$ \\
Q1 & BELZ-0 & $1 \sim 6 \mathrm{~m}^{3} / \mathrm{h}$ & $0.5 \%$ \\
\hline
\end{tabular}

Tests were performed for different shaft speeds $(600 \mathrm{rpm}, 1000 \mathrm{rpm}$, and $1480 \mathrm{rpm})$ with various pressure differentials up to 80 bar. The pump parameters were also measured to reproduce the gear profile in simulation. The comparisons between outlet pressure oscillations and outlet flow oscillations are reported in the following part of this section.

Two representative cases of the outlet pressure oscillations and outlet flow oscillations comparisons are shown in Figure 9 and 10. Figure 9 shows a high-speed and high-pressure case, in which the outlet pressure and flow behavior are exhibited: for different center distance deviations, the outlet pressure oscillations are match the experiment, however, the outlet flow rate have great oscillations, and the flow behavior is same to the case of center distance deviation 0 to $0.01 \mathrm{~mm}$. While Figure 10 shows a low-speed and low-pressure case, in which the outlet pressure and flow behavior are exhibited: for different center distance deviations, the outlet pressure of simulation have not any change, but the outlet pressure of experiment has oscillations, as well as the outlet flow result of experiment is greater than the simulation.

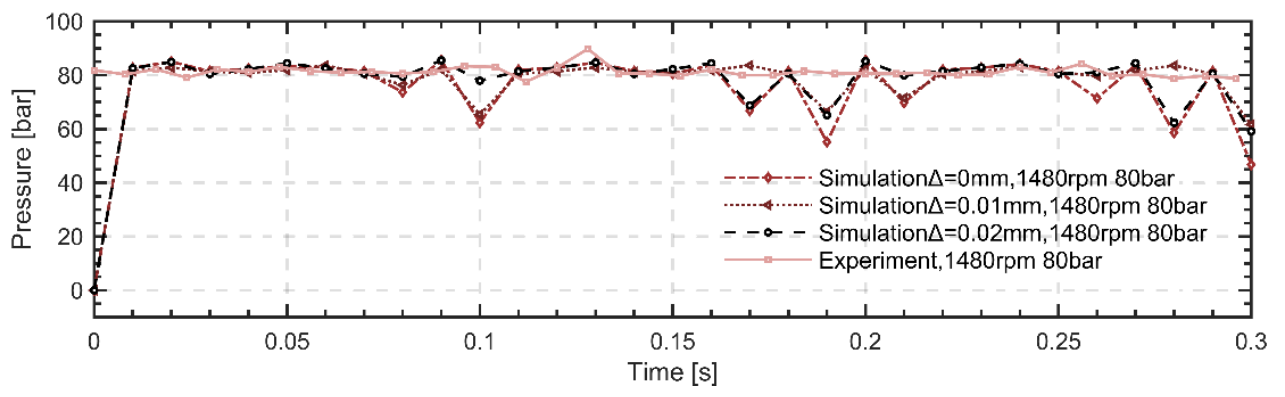

(a) 


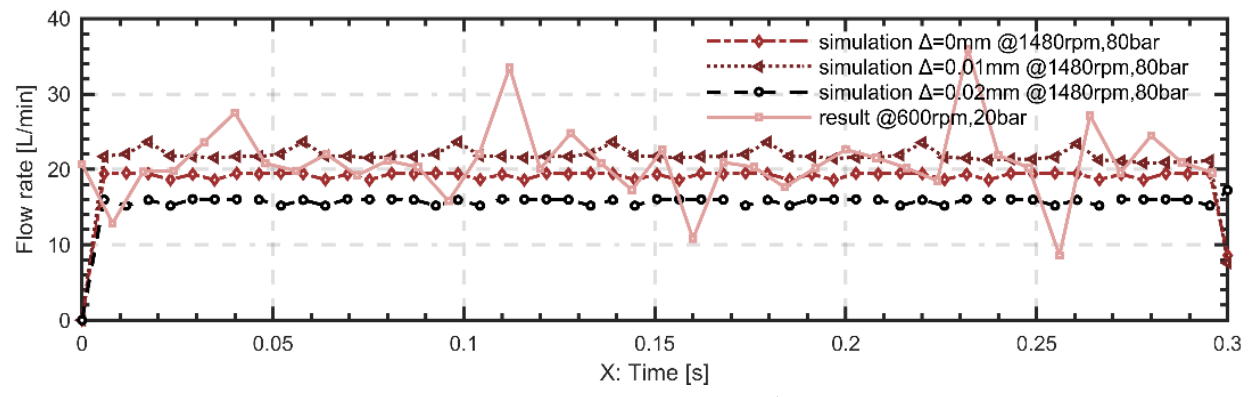

(b)

Fig. 6. Comparison of the simulated and experimental measured pressure and flow rate at $1480 \mathrm{rpm}$ and 80 bar. Behavior of the

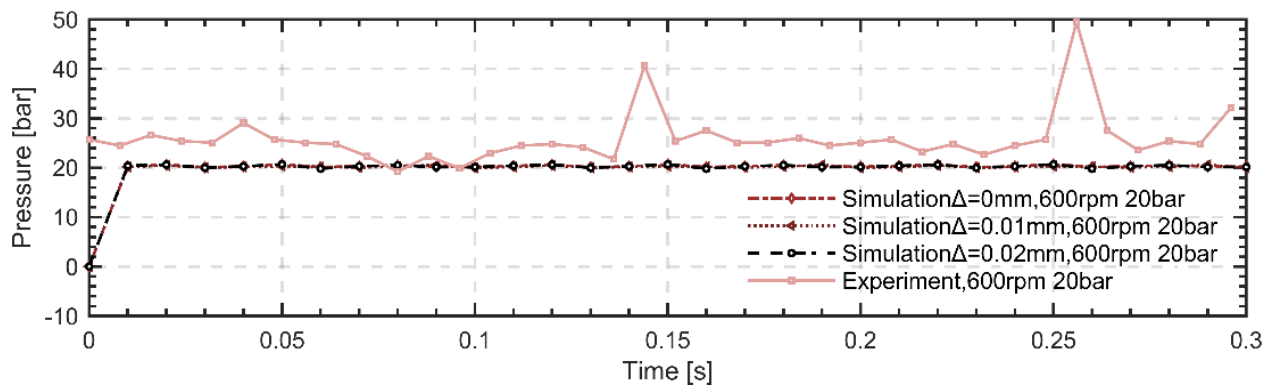

(a)

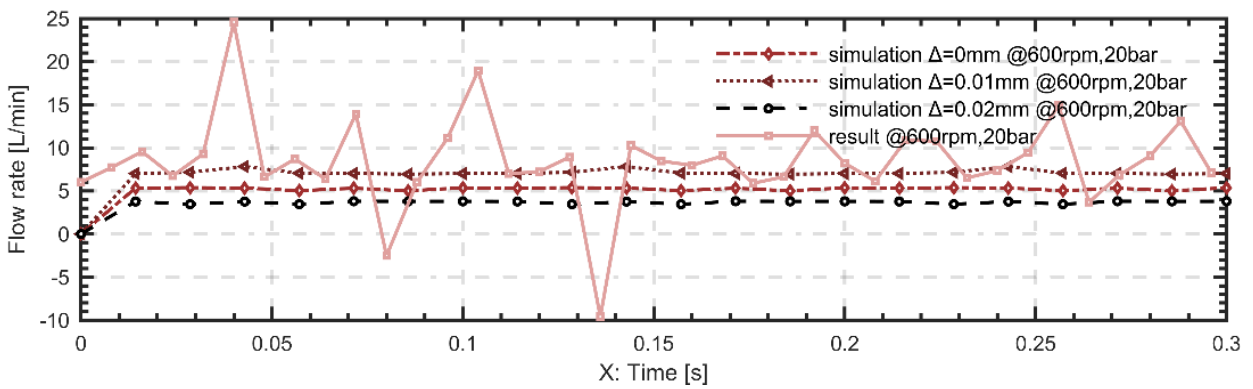

(b)

Fig. 7. Comparison of the simulated and experimental measured pressure and flow rate at $600 \mathrm{rpm}$ and 20 bar. Behavior of the outlet pressure oscillations (a) and outlet flow oscillations (b) are shown.

\section{Conclusions}

This paper presents an experiment and numerical approach of modeling circular-arc gear pumps considering the center distance deviation. A review on the gear profiles design of circular-arc gear pumps was first provided, and the numerical modeling of circular-arc gear pumps then described. This numerical approach for modeling the geometric evolutions of the displacement chambers permitted to study the kinematic flow ripple of circular-arc gear pumps. The numerical model of an arc gear pump was established, in which the arc tooth profile can be accurately obtained, and the center distance deviation was considered in advance. In different center distances, the pressure ripple and flow ripple have been carried out in the light load condition and in the medium load condition with outlet pressures of 20, and $80 \mathrm{bar}$ and the constant rotational speed of $600 \mathrm{rpm}$ and $1480 \mathrm{rpm}$. The results show that with the increase of center distance deviation, the outlet flow rate of the arc gear pump increases first and then decreases greatly. The center distance deviation has little effect on the independent tooth cavity pressure. In the final section of the paper, the proposed fluid dynamic model is used to simulate a commercial circular-arc gear pump, which was tested within this research for modeling validation purposes. The simulated outlet pressure and outlet flow ripple are compared against the measured values. The comparisons highlight the validity of the proposed simulation approach. Next, the model can be used to gain further insights on the circular-arc gear pump operation, such as including localized cavitation, internal flow leakages. In order to give full play to the good transmission performance of the arc gear pump and prevent excessive 
dynamic impact due to the center distance deviation, the dynamic response caused by the center distance deviation can be adjusted by optimizing the machining accuracy and assembly accuracy of the arc gear.

240

\section{References}

[1] Costa, G. K., \& Sepehri, N. (2018). Understanding overall efficiency of hydrostatic pumps and motors. International Journal of Fluid Power, 19 (2), 106-116.

[2] Choudhury, S. K., Sa, P. K., Bakshi, S., \& Majhi, B. (2016). An evaluation of background subtraction for object detection vis-a-vis mitigating challenging scenarios. IEEE Access, 4, 6133-6150.

[3] M.A. Morselli, La drastica evoluzione segnata dalle pompe a "contatto continuo": Part 1, Oleodinamica e Pneumatica, January 2005 (in Italian).

[4] Chen, C. O. K., \& Yang, S. C. (2000). Geometric modelling for cylindrical and helical gear pumps with circular arc teeth. Proceedings of the Institution of Mechanical Engineers, Part C: Journal of Mechanical Engineering Science, 214(4), 599-607.

[5] Zhou, Y., Hao, S., \& Hao, M. (2016). Design and performance analysis of a circular-arc gear pump operating at high pressure and high speed. Proceedings of the Institution of Mechanical Engineers, Part C: Journal of Mechanical Engineering Science, 230 (2), 189-205.

[6] Manring, N. D., \& Kasaragadda, S. B. (2003). The theoretical flow ripple of an external gear pump. J. Dyn. Sys., Meas., Control , 125 (3), 396-404.

[7] Huang, K. J., \& Lian, W. C. (2009). Kinematic flowrate characteristics of external spur gear pumps using an exact closed solution. Mechanism and Machine Theory, 44 (6), 1121-1131.

[8] Zhao, X., \& Vacca, A. (2017). Formulation and optimization of involute spur gear in external gear pump. Mechanism and Machine Theory, 117, 114-132.

[9] Rundo, M. (2017). Models for flow rate simulation in gear pumps: A review. Energies, 10 (9), 1261.

[10] Rana, D., \& Kumar, N. (2014). Experimental and computational fluid dynamic analysis of external gear pump.

International Journal of Engineering Development and Research, 2 (2).

[11] Zhao, X., \& Vacca, A. (2018). Analysis of continuous-contact helical gear pumps through numerical modeling and experimental validation. Mechanical Systems and Signal Processing, 109, 352-378.

[12]A. Vacca, M. Guidetti, Modelling and experimental validation of external spur gear machines for fluid power applications, Simul. Model. Pract. Theory19 (9) (2011) 2007-2031.

[13]AMESim 4.2 User Manuel. <http://nupet.daelt.ct.utfpr.edu.br/ontomos/paginas/AMESim4.2.0/doc/pdf/manuals/amesim.pdf>.

\section{Declaration}

\section{List of abbreviations}

$N \quad$ the number of teeth

$\theta_{\mathrm{A}} \quad$ the angle $\angle \mathrm{MO}_{1} \mathrm{~A}$

$\theta \mathrm{C} \quad$ the angle $\angle \mathrm{MO}_{1} \mathrm{C}^{\prime}$

$\theta_{\mathrm{B}} \quad$ the angle $\angle \mathrm{MO}_{1} \mathrm{~B}^{\prime}$

$r \quad$ the radius of the base circle

$r_{1} \quad$ the radius of the base circle of driving gear

$r_{2}$ the radius of the base circle of driven gear

$r_{a}$ the addendum radius of gear

$r_{\mathrm{f}} \quad$ the root radius of gear

$\alpha \quad$ the angle $\angle \mathrm{Q}^{\prime} \mathrm{O}_{1} \mathrm{M}$

$\varphi_{1} \quad$ a parameter related to the arc angle of the $\mathrm{AB}$ segment

$\varphi_{2} \quad$ a parameter of the arc angle of the CD segment

$\Delta L \quad$ center distance deviation

$\beta \quad$ the spiral angle 


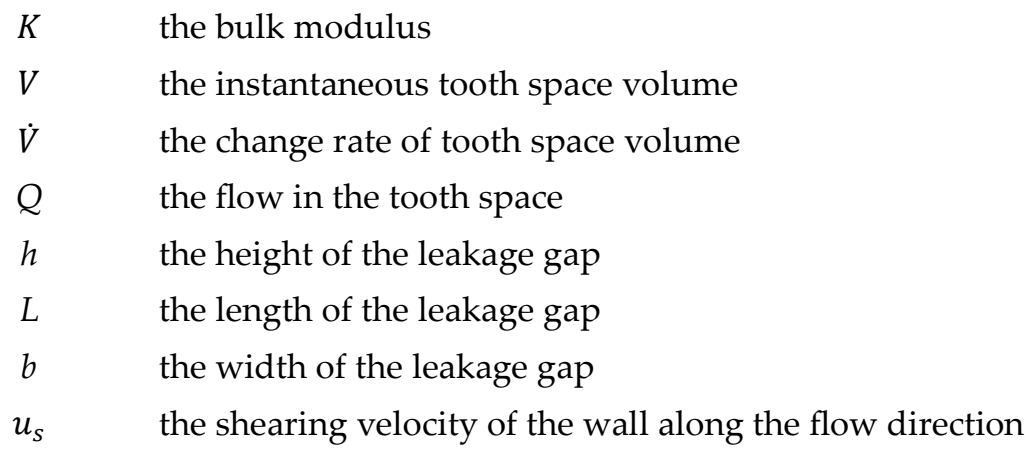

Ethics approval and consent to participate

Not applicable.

\section{Consent for publication}

Not applicable.

\section{Availability of data and materials}

The datasets used and/or analysed during the current study are available from the corresponding author on reasonable request.

\section{Competing interests}

The authors declare that they have no competing interests

\section{Funding}

The authors received no financial support for the research, authorship, and/or publication of this article.

\section{Authors' contributions}

Xiaoling WEI has provided the design of the work, and has acquired and analyzed the data. Yongbao FENG has substantively revised it. Zhenxin HE has interpreted the data. Ke LIU has used the software to achieve the goal in the work.

\section{Acknowledgements}

This work has been developed in the Shandong Shijing Machinery Co., Ltd. The authors wish to thank Qingwu MENG and Guangzhi ZHANG for providing the experimental equipment and technical support.

\section{Authors' information}

$\mathrm{W}$ is a PhD candidate at Rocket Force University of Engineering. She has engaged in intelligent hydraulic components design and hydraulic system analysis for 8 years.

$\mathrm{F}$ is a doctor. He is currently a professor at Rocket Force University of Engineering. His research interests include the equipment launch technology, hydraulic technology and other related fields.

$\mathrm{H}$ is a doctor. He is a lecturer at Rocket Force University of Engineering. His research interests include modeling, simulation and control of electro-hydraulic systems, and lifting robot technology.

$\mathrm{L}$ is a postgraduate at Rocket Force University of Engineering. His research interests include intelligent hydraulic components design. 